\title{
Research on intercultural adaptation of Chinese enterprise personnel in Saudi Arabia
}

\author{
Guangcun Zhao ${ }^{1,2,3}$ \\ ${ }^{1}$ Associate professor, Department of Foreign Languages, Bozhou University, China \\ ${ }^{2}$ Doctoral student, Guangdong University of Foreign Studies, China \\ ${ }^{3}$ Center for Foreign Literature and Culture, Guangdong University of Foreign Studies 510420, China \\ Correspondence: Guangcun Zhao, Center for Foreign Literature and Culture, Guangdong University of Foreign \\ Studies 510420, China. E-mail: fentaizhaoguangcun@163.com
}

Received: June 25, 2019

doi:10.5539/hes.v9n3p105
Accepted: July 18, 2019 Online Published: July 27, 2019

URL: https://doi.org/10.5539/hes.v9n3p105

\begin{abstract}
Chinese enterprise personnel are faced with the problem of intercultural adaptation. Based on Black's theory of "three-dimensional" model of intercultural adaptation, this paper proposes a "four-dimensional" model of intercultural adaptation, namely, life adaptation, work adaptation, interpersonal adaptation and Chinese image adaptation. The research method of semi-structured in-depth interview is used to interview 23 Chinese people from one Chinese enterprise in Saudi Arabia, who have worked there for at least one year. We get findings as follows: (1) Life adaptation: maladjustment is mainly reflected in religious restriction. Especially, religious regulations and taboos make the life of Chinese enterprise personnel restricted. However, there are also many aspects of adaptation, such as Saudi cuisine, living environment and leisure life, which bring the satisfaction of life demands to Chinese enterprise personnel. (2) Work adaptation: foreign companies must employ a certain proportion of local people to work in their companies; the roles of buyers and sellers in Saudi Arabia and in China are different; the concept of time is different. (3) Interpersonal adaptation: Chinese people in Saudi Arabia still have the most frequent contact with their Chinese compatriots, and it is difficult for them to develop close friendship with foreigners. Chinese people are good at creating harmonious interpersonal relationships for work through some after-work activities, such as drinking tea, eating out and holding football matches. (4) Chinese image adaptation: Chinese enterprise personnel in Saudi Arabia have decent income, and Saudi police fail to check Chinese cars, all of which make the Chinese people have a positive face value.

In view of the above four adaptation situations of Chinese enterprise personnel in Saudi Arabia, the following suggestions are proposed: (1) Be strict with yourself in life, respect local social and religious customs, and also keep a careful attitude and actively deal with disadvantageous factors. (2) While benefiting from working or doing business in Saudi Arabia, we should make contributions for the development of local economy and society, providing employment and training for local people. (3) We should observe the local laws and regulations, and also follow the local and international market rules. (4) In interpersonal communication, we should combine the maintenance mode of Chinese "guanxi" (relationship) with western "principle" on the one hand, and make a difference between them on the other hand. (5) In terms of image adaptation, besides maintaining a good image politically and economically, it is also necessary to improve our individual quality and our cultural cultivation overseas, be a communicator bridging Chinese and foreign excellent culture, and build a positive national image and individual image.
\end{abstract}

Key words: Chinese enterprise personnel, intercultural adaptation, "four dimensional" model, Saudi Arabia

\section{Introduction}

In the context of China's "Belt \& Road" initiative and Chinese enterprises' "going out" strategy, it would be meaningful to discuss Chinese enterprises' intercultural adaptation in Saudi Arabia. The author chooses Saudi Arabia as the research background because China puts forward the "Belt \& Road" initiative and Saudi Arabia has the 2030 vision. Under the social environment of the two countries, more and more Chinese individuals or enterprises will do business or undertake projects in Saudi Arabia. In a different cultural background, an individual must have the problem of intercultural adaptation. Besides, the author has several friends in Saudi 
Arabia, providing help for my research. Saudi Arabia is a special society, which desires to integrate into the modern society, and holds strong belief in the traditional religion as well. The tension between acceptance and rejection of the two sides will inevitably affect the cultural adaptation of Chinese enterprise personnel in Saudi Arabia. What is the adaptation situation of Chinese enterprise personnel in Saudi Arabia? What is the underlying cause of intercultural adaptation problems? What response mechanisms should be adopted to solve the intercultural adaptation problems? In this study, the qualitative research method was used to conduct semi-structured in-depth interview with 23 Chinese enterprise personnel (22 males and 1 female) who have worked in Saudi Arabia for at least one year. Then, on the basis of Black's "3 dimensional" model theory of intercultural adaptation, according to the data collected, this paper proposes the "four dimensional" model theory of intercultural adaptation of Chinese enterprise personnel in Saudi Arabia, namely, life adaptation, work adaptation, interpersonal adaptation and Chinese image adaptation. By searching the literature, it is found that up to now, no scholars have studied the intercultural adaptation of Chinese enterprise personnel in Saudi Arabia with qualitative research method. Therefore, this study is somewhat innovative.

Table 1. Interviewees' Individual Information

\begin{tabular}{llllll}
\hline Name & Gender & Age & Position & Diploma & Years in KSA \\
\hline No.1 W & male & 42 & DDM & Bachelor & 1 \\
No.2 W & male & 34 & Vice Director & Bachelor & 3.5 \\
No.3 Z & male & 36 & Deputy Manager & Bachelor & 8 \\
No.4 L & male & 50 & Office Director & College & 7 \\
No.5 X & male & 37 & Technician & Bachelor & 8 \\
No.6 L & male & 44 & Deputy Manager & Bachelor & 4 \\
No.7 X & male & 52 & AGM & Master & 7 \\
No.8 W & male & 56 & Project Manager & Bachelor & 8 \\
No.9 L & male & 36 & DEM & Bachelor & 4 \\
No.10 X & male & 38 & DCM & Master & 3 \\
No.11 C & male & 34 & Warehouse Supervisor & Bachelor & 6 \\
No.12 Z & male & 50 & Project Manager & Bachelor & 3 \\
No.13 H & male & 52 & Engineering Supervisor & Master & 2 \\
No.14 W & male & 39 & AMMP & College & 4 \\
No.15 Y & male & 35 & Administrative Personnel & Bachelor & 3 \\
No.16 C & male & 35 & Budgeting Personnel & College & 5 \\
No.17 G & male & 36 & DFM & Bachelor & 1.5 \\
No.18 Y & male & 27 & Engineer & Bachelor & 1.5 \\
No.19 Y & male & 42 & Senior Engineer & Bachelor & 2 \\
No.20 L & male & 29 & Administrative Personnel & College & 1 \\
No.21 Li & male & 37 & Administrative Personnel & Bachelor & 1 \\
No.22 L & male & 32 & Designer & Bachelor & 1 \\
No.23 C & female & 33 & Administrative Personnel & Bachelor & 2 \\
\hline
\end{tabular}

Notes: DDM referring to Department Deputy Manager; AGM, Assistant General Manager; DEM, Deputy Engineering Manager; DCM, Deputy Commercial Manager; AMMP, Assistant Manager of Material Purchasing; DFM, Deputy Finance Manager.

\section{Theoretical Basis}

\subsection{Definition of Intercultural Adaptation}

According to Ward (1997), foreign researches on intercultural adaptation originated in the late 1950s. There are many research perspectives, some focus on the cultural awareness and viewpoint maturity from the perspective 
of individuals. Some explore from the perspective of social relations, mainly studying the acceptance of local culture by outsiders or the quality of relations with local people. Some focus on personal development and identity from the perspective of self-positioning. Some explore from the completion of tasks, mainly on research work and academic achievements. Some explore from psychological factors, mainly on people's life satisfaction and emotional state. Some focus on the acquisition of appropriate cultural and communication skills from the perspective of behavior (Shi, 2010: 5-6).

American anthropologist Robert Redfield et al. believed that intercultural adaptation is a change of two cultural patterns caused by the continuous contact between groups with two different cultures (Wang, 2011). Intercultural adaptation in a broad sense refers to the process of improving our own adaptation level to meet the requirements of the new cultural environment (Kim, 1988: 273-294). Kim (2001) believed that intercultural adaptation refers to the adaptation of outsiders to the new social and cultural environment in the process of short-term stay, settlement, subculture migration and social change (Shi, 2010: 5-6). Intercultural adaptation solves the problem of how sojourners or new immigrants experience frustration caused by the mismatch and incompatibility between the target culture and their own culture. In other words, cross-cultural adaptation is a process of coping with the inadaptability in the target culture (Chen \& Starosta, 2007: 164).

Gudykunst \& Kim (2007: 358-360) believe that the process of intercultural adaptation is the process of pushing and pulling between "deculturalization" and "enculturation". The final direction of intercultural adaptation is assimilation, a highly enculturated and highly deculturalized state. On this basis, Kim believes that intercultural adaptation is a dynamic process, a process of pressure and growth. Pressure is a necessary condition for the generation of adaptive change, an internal driving force for the generation of adaptive change, which can realize the spiritual growth of individuals after entering a different culture. Stress, adaptation and growth are the essence of the individual's intercultural adaptation process. These three elements together constitute a three-dimensional dynamic mental activity curve moving above the syncline. Instead of a smooth straight line, the figure is a coiled spring that moves two steps forward and one step back, pushing forward under pressure. This model reflects a dialectical relationship such as push and pull, change and stability, participation and separation (Qiu \& Xiao, 2018).

In short, intercultural adaptation is the process of "crossing" the mother cultural environment into the new and strange one to constantly overcome the problems caused by cultural differences and adapt to and integrate into the new cultural environment from the psychological and social levels. In this process, the original "cultural package" and the new "cultural package" are constantly pushed and pulled, fighting against each other, influencing each other and borrowing something from each other. As a result, the shared cultural region of both sides is getting larger and larger, and intercultural adaptation is becoming better and better. In terms of the theory of intercultural adaptation, foreign scholars are obviously ahead of domestic ones, such as the theory of cultural shock and the theory of U-shaped curve proposed by Oberg (1960), the dimension theory of intercultural adaptation proposed by Mansell (alienation, marginalization, adaptation, and duality), Berry's acculturation strategy management theory, and Chen Guoming's marginal model of intercultural adaptation. However, exploring intercultural adaptation from the structural perspective, i.e. dividing it into several specific dimensions, Ward's theory of two-dimensional intercultural adaptation and Black's theory of three-dimensional intercultural adaptation are preferred.

\subsection{Research on Dimensions of Intercultural Adaptation}

Most researchers agree with the view of Ward and his colleagues' classification of intercultural adaptation, i.e. two dimensions of intercultural adaptation: psychological adaptation and social adaptation. Psychological adaptation is based on emotional response, which refers to mental health and life satisfaction in intercultural contact. In the process of intercultural contact, if there are no or less negative emotions such as depression, anxiety, loneliness and disappointment, psychological adaptation can be achieved. Social adaptation refers to the ability to adapt to the local social and cultural environment and to effectively contact and communicate with people with local culture. Black further divided intercultural adaptation into three dimensions: general adaptation, work adaptation and interact adaptation. General adaptation refers to the adaptation to life in a foreign culture, including daily life related food, housing, living expenses and health care. Work adaptation means to be familiar with new work tasks, work roles, work responsibilities and work environment. Interact adaptation refers to the feeling of comfort and proficiency in social communication with people in the host country. It is usually the most difficult for the sojourners to reach, because the cultural differences between the two parties seem insurmountable in direct communication with the people in the host country (Wang, 2011).

Based on Black's "three-dimensional" model theory of intercultural adaptation, this study puts forward a 
"four-dimensional" model theory of Chinese enterprise personnel adapting in Saudi Arabia, including life adaptation (food and shopping, environment and climate, security, amateur life), work adaptation (fulfilling the task of employing Saudi Arabians, sellers' market, concept of time), interpersonal adaptation (officer-friend relationship, colleague-centered friend circle, difficult-to-easy domestic contact, making friends by playing soccer) and the Chinese image adaptation (sweeping goods egoistically, decent salary income, the local police failing to check Chinese cars).

\section{Intercultural Adaptation of Chinese Enterprise Personnel}

\subsection{Life Adaptation}

Adaptation is the most important and basic need for sojourners. For example, food and shopping, environment and climate, safety issues, and leisure life are all necessary for the sojourners to lead to a basic, comfortable and colorful life in a different cultural environment. In the interview, in terms of the interviewees' life experience in Saudi Arabia, two words are mentioned frequently, i.e. boring and monotonous. However, it seems to be a paradox that when they were in Saudi Arabia, they found the life there is boring and monotonous, and once they returned from Saudi Arabia, staying in China for a period of time, they begin to miss the life in Saudi Arabia. Taken together, the vast majority of Chinese enterprise personnel can adapt to the life in Saudi Arabia, and some even have the idea of emigrating there. In other words, Chinese personnel's life in Saudi Arabia is both boring and charming.

\subsubsection{Food and Shopping}

Food and shopping is indispensable for an individual to work and live abroad. For Chinese enterprise personnel, it is a special and unforgettable experience. There is something inconvenient and inadaptable, and also something interesting and adaptable.

\subsubsection{Quality Canteen Meals and Specific Saudi Flavor}

People consider food as the most important and the need for food is fundamental to people. The Chinese personnel working in the Saudi project department site have high food standards. The food preferences of employees from different parts of China are taken into consideration, so chefs from home who are good at cooking food with different flavors in China, including Sichuan food, Hunan food and Cantonese food, are invited to Saudi Arabia to cook meals for Chinese enterprise personnel. "I'm sure I'll be able to eat food with home flavor", said Mr. Y. (Interviewee No. 15, Y, male, 35, administrative personnel) In addition, some Saudi Arabia's Islamic cuisine, such as braised mutton and hand-grabbed mutton rice, is also popular among Chinese employees.

\subsubsection{Quality and Cheap Beef, Mutton and Seafood}

The project site is not far from the Red Sea, so the seafood is cheap. Beef and mutton, which are expensive and rarely eaten in China, are cheap and easy to get access in Saudi Arabia. Some interviewees say it will be better if they can drink wine while eating which can relieve their fatigue of work, but drinking alcohol is forbidden and illegal in Saudi Arabia. So they cannot drink while eating. In their daily meals, they can often eat mutton, beef, and seafood. So, the staff food standards are higher than those in China.

\subsubsection{Men and Women Being Seated in Separate Areas While Eating out}

When eating out in Saudi Arabia, men and women are separated. The restaurant is divided into the single area and the family area. If a man or a group of men go to a restaurant, they should sit in the single area. If it's a family, or if there is a female among the diners, they can be allowed to eat in the family area. The environment of the single area is relatively open, while the family area is relatively closed. The latter can be a private room, or a relatively closed space surrounded with curtains. The two areas are separated.

\subsubsection{Inconvenience of Eating during Ramadan}

It is a little inconvenient while eating out during Ramadan. In the whole month, Muslims are not allowed to eat or drink food between sunrise and sunset. Also, you can't eat, drink or smoke in public during Ramadan. Therefore, many restaurants are closed during this period of time in the day. Though there are still a few restaurants run by Americans or other non-Muslims from other countries open as usual, it still causes a certain amount of trouble for Chinese employees dining out during the month of food fasting.

\subsubsection{Shopping Family Day in Saudi Arabia}

Friday and Saturday are usually shopping "family day", allowing only females to enter the mall shopping, especially some large malls. However, if you are accompanied by a female, or persistent in entering, you can 
also be allowed in because "religion is just a form. In general, the supermarket has three doors, left, right, and front. Singles are not allowed in, but if they are persistent, sometimes the supermarket staff will turn a blind eye", said Mr. X (Interviewee No. 5, X, 37, technician).

\subsubsection{Environment and Climate}

Desert takes up a large part of Saudi Arabia, so one of the most obvious characteristics of its environment and climate is dry with high temperature. However, the site of the Chinese project department is on a small plateau, with comfortable environment and climate. Clouds are easy to form, and sometimes, especially in the afternoon, it will rain for an hour or two, then it gets fine quickly, driving the dryness and high temperature away.

\subsubsection{Best Resort in Saudi Arabia}

Chinese enterprise staff work and live on a small plateau in Saudi Arabia, at an altitude of around 2,000 meters, about the same as the Yunnan-Guizhou Plateau in China. The region, with its dry, cool air and spring-like weather, is one of the best Saudi resorts, and every year many Saudis come here from far away for the holidays.

\subsubsection{Slight Altitude Sickness}

Some Chinese employees will have altitude sickness when they go there for the first time, with symptoms such as nosebleeds, lack of oxygen and slow walking. In comparison, the altitude sickness was less intense among the young and the strong, who can also adapt to the climate more quickly. However, the employees who are a little older and weaker have a much worse altitude sickness and the adaptation period is relatively longer.

\subsubsection{Mosque Broadcasting}

At around 5 in the morning every day in Saudi Arabia, while Chinese employees are still sleeping, the broadcasting sound of convening Muslims to pray comes from nearby mosques. Loud sounds can wake one from a dream, and even be startled to wake up for the first time. But over time, they will gradually adapt to this kind of sound, and even feel unaccustomed if they fail to hear the sound of mosque broadcasting.

\subsubsection{Security Problems}

The security problems haunted in Chinese enterprise personnel are the dangers that they will probably violate rigid doctrines and taboos, together with the influence of the ceaseless war between Saudi and Yemen. Actually, the security situation of Saudi Arabia is quite good and the ceaseless war between Saudi and Yemen does not exert great influence on the life of ordinary people.

\subsubsection{Rigid Doctrines and Various Taboos}

Saudi Arabia is a relatively closed country which is considered to be the sovereign state of Islam. It has rigid doctrines and various taboos. For examples, strange men and women can not talk to each other; you can't take photos of women and religious places; eating, drinking or smoking is not allowed in the day during Ramada; you are forbidden to drink alcohol, eat pork, and so on. Violators will be punished. In addition, religious police, police in plain clothes, public security police, traffic police and other forces maintain social order. Therefore, public security in Saudi Arabia is good. However, due to the strict religious doctrines and various taboos, it is inevitable that Chinese employees in Saudi Arabia will violate the doctrines and taboos, thus causing unnecessary trouble.

\subsubsection{The Small War between Saudi Arabia and Yemen}

The small war between Saudi Arabia and Yemen has lasted on and off for years, but there is still no sign of ceasefire. The Chinese project department site is closer to the war zone, occasionally shells flying to and fro over their heads, which also makes the Chinese employees feel a little uneasy. Fortunately, the working area of Chinese employees is not the war zone, and they can stay out of it. Therefore, it does not actually exert great influence on their daily life and work.

\subsubsection{Abundant and Colorful Entertainment Activities}

Saudi Arabia is a religious country, so some entertainment activities are prohibited. Therefore, it is necessary to overcome the feeling of loneliness, boredom and monotony in Saudi Arabia. Both the project department and individual employees have thought of many ways to keep happier and healthier. For example, "going outing on the weekend, having a dinner for the Spring Festival, having a holiday dinner, having a little party, having a lottery, that's it" (Interviewee No. 23, C, female, 33, administrative personnel). "There's a recreation room, a ping-pong room, and a gym. At weekend, we can also go out for sightseeing" (Interviewee No. 13, H, male, 52, engineering supervisor). "We have nothing to do in the evening, and nothing to do except watching a movie and having some tea with my colleagues" (Interviewee No. 11, C, male, 34, warehouse supervisor). "We can either 
chat or watch movies online. Or we choose to surf the Internet, go out to dinner, or go shopping around the mall. Basically activities like these" (Interviewee No. 9, L, male, 36, assistant engineering manager). "If time permits, I will also go to the neighboring countries, such as Egypt, Bahrain, Qatar and Dubai. It's all around. It's all around Saudi Arabia" (Interviewee No. 10, X, male, 38, deputy commercial manager). Many of the employees mentioned the Red Sea fishing, which is a wonderful experience in life. In addition, young employees are keen on fitness, creating a fitness fad. They Use exercise to kill the free time, and find an outlet for the boredom in that environment, which also boosts relationships and keeps them healthy and energized.

In sum, Chinese enterprise personnel can generally adapt to living in Saudi Arabia. Although there are gender separation and inconvenience while eating and shopping, a few employees' complaint that Saudi food is too oily and too sweet, some employees having experienced altitude sickness, strict religious taboos and customs, and so on, most of them can be overcome or avoided. There are many positive factors that help Chinese people adapt to Saudi life well. In terms of food, besides eating food with home flavor in the dining hall, Saudi special beef and mutton, seafood, braised mutton and hand-grabbed mutton rice are also popular among Chinese people. As to climate and environment, the location of the project department is a small plateau with comfortable weather, which is the best resort in Saudi Arabia. In terms of the sporadic local war between Saudi Arabia and Yemen, it only leads to slight mental panic of the enterprise personnel. In fact, it can not pose great threat to their daily life and work. In addition, the leisure life is rich and colorful, such as various entertainment activities, ball games, Red Sea fishing, fitness, shopping, and so on, which can relieve the lonely life in Saudi Arabia.

However, the Saudi society has changed a lot recently, especially from 2017 and now the Saudi society has been more open than before. For example, the religious police are abolished; men and women can talk and communicate with each other in public; there are still family-only shops, however, most of the shops are free for customers to shop around; though there are still single and family areas in a restaurant, more and more restaurants have removed the barriers; you can do some shopping any time in a week, and family day is gradually disappearing. All of the changes are providing a free and favorable environment for foreigners to live and work in Saudi Arabia, which are conducive to their adaptation in a different cultural background.

\subsection{Work Adaptation}

The work adaptation here mainly refers to several topics directly or indirectly related to work mentioned by interviewees, such as fulfilling the task of employing the proportion of Saudi Arabians, sellers' market, and the concept of time.

\subsubsection{Employing a Certain Proportion of Local People}

The Saudi government encourages local people to go to work or do business. Thus, it is also a policy that foreign companies in Saudi Arabia have the duty to employ a proportion of local people to work in their companies according to their total number of employees (at least 5\%). It is linked to the signature of work visa. In other words, the approval of the foreign companies' work visa application is closely related to the employment of the local people. It is very natural and reasonable for foreign companies to make contributions to the social development of the target country. However, it is a fact that a few of the local people employed by the company are not qualified for their jobs and failed to complete the tasks assigned to them. So how to change these peoples' work attitude and train to make them competent in their posts in a short period of time is a problem.

\subsubsection{Sellers' Market in Saudi Arabia}

In the domestic market, the customer is served and the supplier is to provide service, because the more commodities sold out, the more profit the sellers will make. This is so-called buyers' market. But in Saudi Arabia, it is not totally the same. In Saudi Arabia, many products and equipments are not produced in Saudi Arabia and they are imported from foreign countries, so there are few agents to choose from. You have enough money, but you are not guaranteed to buy what you want or the commodities and equipments ordered can be delivered in time. Many Chinese company executives know little about Saudi Arabia's market, still believing it is similar to Chinese market and that if they have money, they can buy what they need. As a result, they suffer a lot. Because the factor of sellers' market in Saudi Arabia is not taken into consideration, they have to stop their work, thus leading to the construction postponement.

\subsubsection{Some Saudi People's Concept of Time}

Some Saudis have a different concept of time from us Chinese, and they consider it natural if arriving late for an appointment or a meeting for everything is determined by Allah and better let it be. Some Saudis, who have studied abroad and received advanced education, are punctual. Most of the Saudis believe in predestination, which means life is arranged by Allah, and that everything is planned by Allah. The same is true of the idea of 
time, and punctuality or lateness is arranged and predetermined by Allah. In addition, Saudis believe in Islam and pray five times a day. They think belief in Allah is the most important.

In sum, the Saudi government has a good welfare policy, offering subsidies to improve its people's livelihood in many aspects. In order to improve local employment, it is ruled that foreign companies in Saudi Arabia should employ a certain proportion of local people, generally at least 5\% of the total employees. Saudi Arabia is a sellers' market, which means the seller plays the dominant role in the process of commodity transaction. The Saudis think religion is the most important and believe everything is predetermined, including time. Thus it is normal to be a little late for an appointment or meeting. So, in shallah is the Saudis' pet phrase, which means it depends.

It is not wrong for every government to protect its people and improve the living standards of its people. Neither is the Saudi government. In the past tens of years, the Saudi government depends on the oil economy and becomes a rich country in the world overnight. The Saudi people benefit a lot from their country's high welfare policy, which also arouses a lot of social problems. For example, some Saudi people do not value education, so they have no competitive skills for a certain post. Also, some Saudis are not willing to do the dirty, tiring or so-called indecent jobs. Luckily, the Saudi government has realized these social phenomena and tried to change the status quo of the Saudi society. It devotes major efforts for the development of education and meanwhile encourages the Saudi people, especially young people to work or do business so that they can support themselves. The Saudi society is a young one, in which young people make up the majority of the population. If their quality can not be improved or most of them have no jobs, it will lead to the instability of the society. So the Saudi government wants foreign companies to employ and cultivate the Saudi people. They think it's a win-win policy, i.e. foreign people make money in Saudi Arabia and they also have the duty to make contributions for the development of the Saudi society. In terms of time concept and sellers' market, it is closely related to its religion. Most of the Saudis believe in predestination and have got used to slow life. In China, generally, work ranks first, family the second and leisure is last. However, in Saudi Arabia, the order of the three aspects is totally different. Maybe in their eyes, religion ranks first, family the second, work follows it and leisure comes the last. As more and more Saudi young guys receive high quality education, or study abroad, their individual quality will be greatly improved, including their knowledge, skills, thinking style, concept of time, and attitude toward work. More and more Saudi people will go to work or do business. Foreign people and local people will coexist and cooperate with each other very well.

\subsection{Interpersonal Adaptation}

Life and work are often mentioned in parallel, but interpersonal communication is also important and necessary. Harmonious interpersonal relationship will help Chinese enterprise personnel adapt to the life and work in Saudi Arabia, and Chinese enterprise personnel will increase their life pleasure and work efficiency. The friend -like relationship between superiors and subordinates makes the interpersonal relationship in a foreign country closer and more familial. Communication with colleagues, relatives and friends at home is unimpeded. Chinese people are good at building a solid and harmonious interpersonal relationship (or guanxi in Chinese) based on the so-called "offline" communication in some non-work occasions (such as playing sports, drinking tea, eating out etc.), which serves as a lubricant for real work.

\subsubsection{Friend-like Relationship between Superiors and Subordinates}

Chinese people have strong blood ties, kinship ties, friendship and geographical complex. Especially far away from home, the circle formed by friends, relatives, classmates, fellow folks, colleagues is a circle of their own, and people outside the circle are outsiders. There is a separation between distant and close, inside and outside. The Chinese people working in Saudi Arabia are compatriots of the Chinese nation, colleagues and comrades in the same boat, sharing weal and woe. Therefore, the whole project department is like a big family. In China, the hierarchical relationship under the state-owned enterprise system changes significantly overseas, and the power distance between people is much smaller, just like a family.

\subsubsection{Colleague-centered Friend Circle}

In a country with a strong religious atmosphere and many taboos, in Saudi Arabia, Chinese employees rarely dare to have deep contact with Saudis or foreign people for the sake of safety. In their work and life, they still have the most frequent contact with Chinese colleagues, while the so-called foreign friends are only friends who are made by cooperating in their work. Once the working relationship is over, the friendship is over, because the topic of the communication is lost, the "smell" of the "congenial" relationship is gone, and the connection is fading (Interviewee No.7, X, male, 52, assistant general manager). 


\subsubsection{Difficult-to-easy Domestic Contact}

When Chinese enterprise personnel first went to Saudi Arabia in 2009, there was no network in the project department, so they had to make international calls if they wanted to contact with people in China. International calls are expensive and the company phone card can only be used for several times. Later, some employees were helped by a Hong Kong colleague to use Nokia phones to surf online. Although the network signal is weak and unstable, they can contact with the outside world after all. To them, even sending a message to the friends or relatives is the happiest thing. The isolated days only lasted for several months. By 2010, companies had networks, and the days of poor communication with the outside world were gone.

\subsubsection{After-work Activities Improving Interpersonal Communication}

Some Chinese employees enjoy playing soccer, and they make arrangements to play soccer with Saudis and other foreign employees working in Saudi Arabia. Playing soccer makes them healthy, increases the joy of life, and helps to make friends, enhancing the relationship and making cooperative partnership harmonious. This kind of "offline" activity helps the "online" communication, thus bettering the development of work. This is also a kind of interpersonal communication method that Chinese people are good at.

In sum, in terms of interpersonal communication adaptation, in such a relatively small space as the project department in a foreign country, the relationship between enterprise leaders and employees is much closer than in China, and the concept of hierarchy between superiors and subordinates is not as obvious as in China. In a special exotic environment, the enterprise leaders and ordinary personnel need to join hands together to cope with the mental and work pressure. They are usually staying with each other, including eating, working, and playing. Especially in the daily life, not in the work space, they have an intimate relationship like friends or family members. The most frequent contact of Chinese enterprise personnel is with colleagues, or other Chinese in Saudi Arabia. It is difficult to form a close friendship with Saudis and other foreigners except for work communication and cooperation. The quality network enables Chinese enterprise personnel to contact with the domestic friends, relatives and families very well. It is a good way for Chinese enterprise personnel to maintain a relatively harmonious interpersonal relationship with foreigners through some activities, such as ball games, tea drinking and other activities.

Chinese enterprise personnel in Saudi Arabia prefer to communicate with Chinese colleagues or Chinese people from other Chinese enterprises in Saudi Arabia. They have the same cultural background. In addition, Chinese enterprise personnel usually live or work in a relatively limited and fixed area, namely the project department site, so it is convenient to contact with their Chinese colleagues and inconvenient to communicate with people from other countries except for the sake of work. Besides, when an individual goes into a strange and different environment, he/she has the inborn sense of self-protection. The person he/she wants to communicate must be the person who is helpful, kind and trustworthy. Once the foreign people become their friends, the sense of their self-protection will reduce. Before that, they prefer to communicate with familiar people. To the Chinese people, communication is to make friends. Making friends is useful for communication or cooperation in the work. Chinese enterprise personnel also make friends with the local people or other foreign people. However, once they are out of the work environment, the topic between them will disappear, so the communication will end.

\subsection{Chinese Image Adaptation}

Some phenomena in Saudi Arabia are hard to be classifies into one of the three kinds of adaptation mentioned above, i.e. life adaptation, work adaptation, and interpersonal adaptation. For instance, sweeping goods egoistically, can be understood as life adaptation for it belongs to the shopping activity. However, the money or income comes from their work, so it can be also understood as work adaptation. Decent salary income should belong to work adaptation, for it is the reward from their work. However, it can also be understood as life adaptation because we can use the income to pay or consume. The Saudi police fail to check Chinese cars, which seems a little more complex than the former two because it can be understood as interpersonal adaptation between Chinese people and the local people. However, underlying the three aspects, there is something in common, namely, face and image. It is clear that the three aspects affect the face and image of Chinese people in Saudi Arabia. Therefore, the author thinks it is reasonable to add them to a new dimension of adaptation, namely, Chinese image adaptation.

\subsubsection{Sweeping to Buy Goods}

The Chinese are sweeping to buy goods in Saudi Arabia. Sweeping here is used to describe the behavior of Chinese enterprise personnel streaming to buy so many goods at a time in Saudi Arabia. Their income is decent, and many goods in Saudi Arabia are duty-free, much cheaper than those at home, such as honey, milk powder, 
perfume, cosmetics, clothing, electronics, watches, saffron, and so on. As a result, many people will spare time to buy some goods before returning to China, such as helping a domestic friend bring some watches back to China (some people even carry more than ten watches at one time), and buy saffron (buying all the saffron in a whole street, even driving up the price of this kind of goods). Such a "sweeping" behavior would make the Saudis think the Chinese have too much money and don't hesitate to spend a lot of money at once. In addition, when they brought the goods back to China, it also shows a lot of face to send relatives and friends, indicating that they seem to make a million after going abroad, and the people who are given gifts will also feel they have face. This is the unique face logic of Chinese people, i.e. a person has face, and the people associated with him also have face, and it is just "one person gains the Tao and the dog rises to heaven"(one person gets rich or promoted, the people associated with him feel proud and can benefit from him) (Zheng, 2012: 107).

\subsubsection{Decent Salary Income}

Chinese workers in Saudi Arabia earn more than 10, 000 RMB a month, though lower than those top managers from Europe, the United States, Japan and South Korea. Compared to employees from other countries working in Saudi Arabia, they have decent salary income. So when they go to the bank to save or transfer money, the sum of their money is more than that of a dozen of foreign employees in total. Even taking into account domestic consumption, workers abroad are paid more than double their domestic salaries. As professor Zheng says, when a person has certain social status and is respected, we say he has face. Generally speaking, the higher the social status one has, the larger the face is (Zheng, 2012:107). In the eyes of the Saudis, the Chinese have a higher status in Saudi Arabia because the Chinese are much more skilled and paid. Therefore, the Chinese feel they have face in Saudi Arabia.

\subsubsection{Saudi Police Failing to Check Chinese Cars}

Every citizen is a card of national image after going abroad. The Chinese have won respect and trust from locals in Saudi Arabia, where most Saudis are friendly to the Chinese. Even when Chinese people drive out, the local police generally do not check them if they see a Chinese car or a vehicle with a Chinese company logo. The special treatment of the Saudi police to the Chinese also makes the interviewees feel proud when they mention the experience.

In sum, Chinese people work hard abroad, suffering from the nostalgia and failing to take care of their family, so it is natural that their wages are correspondingly much higher, about twice as much as at home. Chinese image adaptation is mainly influenced by political, economic and cultural factors. Saudi Arabia has many duty-free goods, such as watches, electronic products, gold jewelry, clothing, medicine and so on, which are very popular with Chinese people. They do not hesitate to spend a lot of money in shopping, and when they go to the bank to save money or send money home, the sum of money is far larger than that of other foreign employees, and the bank staff will provide special service for Chinese people. Chinese cars are exempt from inspection when the Saudi police see them with Chinese company logos, or when they see cars driven by Chinese people. All of these make the Chinese think they have a good face and win great respect in Saudi Arabia. Individual image and national image are closely interrelated. This is also a very important positive factor for Chinese business personnel to adapt in Saudi Arabia.

\section{Conclusions and suggestions}

The above is the specific description of Chinese enterprise personnel's intercultural adaptation on four dimensions in Saudi Arabia as follows. Firstly, life adaptation: (1) there is still a gender separation and time limitation while eating and shopping; (2) there are many religious taboos, including a ban on eating pork, drinking alcohol, gazing or talking with Saudi women, photographing a mosque or a woman, and eating or drinking in the day during Ramadan; (3) plateau sickness, the sporadic and ceaseless Saudi-Yemen war, and other disadvantageous factors will affect their adaptation, especially at the beginning of their stay in Saudi Arabia. However, there are also many aspects of adaptation, such as Saudi cuisine, living environment and leisure life, which bring the satisfaction of life demands to Chinese enterprises. Therefore, Chinese enterprise personnel can basically adapt to living in Saudi Arabia, both physically and spiritually. Secondly, work adaptation: (1) a few local employees employed by Chinese companies are not competent in the tasks assigned; (2) in the sellers' market, the buyers have to urge delivery all the time; (3) some Saudis have a poor sense of time, and it is not uncommon to be late for a meeting or an appointment. Thirdly, interpersonal adaptation: (1) Chinese people in Saudi Arabia still have the most contact with Chinese people, and it is difficult for them to develop close friendship with foreigners; (2) the interpersonal distance between superiors and subordinates in foreign countries is much closer than that in China; (3) Chinese people are good at creating harmonious interpersonal relationships for work through some after-work activities, such as drinking tea, eating meals and holding football 
matches. Lastly, Chinese image adaptation: (1) Chinese people in Saudi Arabia have decent income, strong purchasing power and large amount of savings or remittances, which are envied by local people and other foreigners; (2) Chinese enterprise personnel's technical ability and professional quality win them respect and trust; (3) Chinese people are trustworthy, and even Saudi police do not check Chinese cars, which makes Chinese people have much face and respect in Saudi Arabia and establish a good national image.

Saudi Arabia is a religious country, the holy land of Islam, so it will adhere to the religious tradition. The king of Saudi Arabia calls himself the servant of two holy cities. Every year, tens of millions of Muslims from all over the world go to pilgrimage to Saudi Arabia and Muslims in Saudi Arabia pray five times a day. In this way, Saudi Arabia is a traditional religious country. Meanwhile, Saudi Arabia still needs social reformation and the Saudi government puts forward the 2030 Vision mainly aimed to get rid of overdependence on oil economy and foreign people, to develop pluralistic economy and encourage more Saudi people to work or do business. In recent years, especially since 2017, the Saudi society has changed a lot. Here is the list of some changes. The religious police have been abolished, and many religious taboos and regulations have gradually lost its effect on people home and abroad. Shopping and eating are more convenient than before. The separation between males and females has turned loose. The efficiency of the Saudi government has improved a lot. The 2030 Vision will make Saudi Arabia more open and competitive. All of the above changes will create a relatively relaxed atmosphere for foreign people to live and work in Saudi Arabia. Of course, in the period of social transition, there are still many problems failing to match the step of reformation. For example, it's correct for the Saudi government to encourage young Saudis to work or do business as soon as possible. However, many of them are still being educated at school or have just entered the society. They need a period of time to get practiced and matured. A lot of Saudis still need to receive vocational training so that they can be competent on all walks of life. Also, in the period of social transition, how to make proper laws and policies to attract more and more powerful foreign companies to invest or do business in a favorable environment, and to balance the relationship between local people and foreign people is still a problem. Just as the saying that nobody is perfect, so no society is perfect. We believe the Saudi society will get better and better.

In view of the above Chinese enterprise personnel's status quo of adaptation in Saudi Arabia, the author puts forward several suggestions. Firstly, discipline in life, observe the local laws and regulations, social customs, religious practices, and cope with disadvantageous factors. Secondly, as Chinese people or Chinese enterprises, while benefiting from working or doing business in Saudi Arabia, we should make contributions for the development of local economy and society, providing employment for local people and vocational training as well. Thirdly, we should observe the local laws and regulations, and follow the local and international marketing rules. We should not apply our original thinking styles or ways of doing things in China to Saudi Arabia. Fourthly, we can use Chinese ways of establishing and maintaining interpersonal relationship with local or other foreign people, bur we should also pay attention to the way of how to keep a harmonious interpersonal relationship in an intercultural context. Fifthly, in terms of image adaptation, compared with face and respect, an individual's personal quality is even more important. Do not give the local or foreign people the impression that Chinese people are full of wealth but short of quality. It is necessary to improve personal cultural cultivation overseas, be a communicator bridging Chinese and foreign excellent culture, and build a positive national image and individual image.

This study also has several limitations, such as the size of subjects, gender discrepancy, and research conditions. The size of subjects is only 23 Chinese enterprise employees who have returned from Saudi Arabia. Among the subjects, there is only one female employee. It is a fact foreign females working in Saudi Arabia are hard to apply for work visas. In addition, Most of the interviewees left Saudi Arabia before or in 2018 and in fact Saudi Arabia has changed a lot since 2017. So their description can not accurately match the fact or phenomena of the current Saudi society. In order to testify whether their description is true or not, the author himself has been in Saudi Arabia for one month to make the survey. And also it is hard to have a comprehensive knowledge of the Saudi society within a short period of time. Thus, there must be unintentional bias or even wrong opinions. But as a scholar, he is interested in Saudi culture and wants to make some research about how to compare and contrast between Chinese culture and Saudi culture. He wants to make some exploration on how Chinese enterprise personnel adapt to the Saudi culture, finding out reasons why Chinese enterprise personnel do not adapt to the Saudi culture, and trying to provide theoretical and practical guidance for Chinese people and Chinese enterprises to work and do business well in Saudi Arabia. This is a long-term major task worthy of further research.

\section{Acknowledgements}

This paper is one achievement of the project named Study of Chinese Enterprise Personnel's Adaptation in Saudi 
Arabia with project number 17QNCX10.

\section{References}

Chen, G. M., \& Starosta, W. J. (2007). Foundations of intercultural communication. Shanghai: Shanghai Foreign Language Education Press. 164.

Gudykunst, W. B., \& Kim, Y. Y. (2007). Communication with strangers: An approach to intercultural communication. Shanghai: Shanghai Foreign Language Education Press.

Kim, Y. Y. (1988). Intercultural adaptation. In M. K. Asante \& W. B. Gundykunst (Eds.), Handbook of international and intercultural communication (pp. 273-294). Newburry Park, CA: Sage.

Oberg, K. (1960). Cultural shock: Adjustment to new cultural environments. Practical Anthropology, 07, 177-182. https://doi.org/10.1177/009182966000700405

Qiu, S., \& Xiao, S. C. (2018). Research on cross-cultural adaptation: foreign important research theories and models. University Education, 03, 101-103.

Shi, X. S. (2010). A study on cross-cultural adaptation of business people abroad. Beijing: University of International Business and Economics Press.

Wang, L. J. (2011). Overview of research on cross-cultural adaptation. Shandong Social Science, 04, 44-49.

Zheng, L. H. (2012). Communication and face game: Research on interactive sociolinguistics. Shanghai: Shanghai Foreign Language Education Press.

\section{Copyrights}

Copyright for this article is retained by the author(s), with first publication rights granted to the journal.

This is an open-access article distributed under the terms and conditions of the Creative Commons Attribution license (http://creativecommons.org/licenses/by/4.0/). 